\title{
PERAWATAN KESEHATAN IBU POSTPARTUM BENTAN PADA ORANG MELAYU DI PONTIANAK : STUDI KASUS
}

\author{
Ummy Yuniantini ${ }^{1}$ \\ Akademi Kebidanan Panca Bhakti Pontianak \\ Email korespondensi : akbidpbpontianak@gmail.com
}

\begin{abstract}
Abstrak
Bentan dalam pandangan orang Melayu Pontianak dapat menyebabkan seorang ibu tidak bisa bangun dari tempat tidur, menggigil, demam, batuk, muntah, berdarah bahkan kematian. Hal tersebut membuat bentan perlu diwaspadai agar bentan tidak terjadi pada diri sendiri dan keluarga pasca melahirkan. Penelitian ini bertujuan untuk menganalisis asuhan kesehatan ibu nifas bentan pada masyarakat Melayu di Pontianak. Penelitian ini menggunakan metode deskriptif kualitatif melalui pendekatan studi kasus. Penelitian ini dilakukan di Kecamatan Pontianak Timur, pada komunitas etnis Melayu kampung Melayu. Pengumpulan data dilakukan melalui observasi, dan wawancara. Hasil penelitian menunjukkan bahwa bentan yang dialami informan disebabkan karena tidak melaksanakan pelayanan kesehatan ibu nifas bagi orang Melayu secara teratur dan patuh. Semakin banyak pelayanan kesehatan yang dilanggar dan tidak dilakukan maka semakin parah rasa sakit yang dialami oleh informan. Kesimpulan dari penelitian ini adalah masyarakat Melayu di Pontianak sangat menjunjung tinggi adat dan tradisinya terutama dalam pelayanan kesehatan pada masa nifas. Jika melanggar, maka ibu nifas harus siap menerima konsekuensi berupa bentan.
\end{abstract}

Kata Kunci: Perawatan Kesehatan, Postpartum, Bentan, Tradisi, Melayu

\begin{abstract}
Bentan in the perspective of the Pontianak Malays can cause a mother unable to get out of bed, shivering, fever, coughing, vomiting, bleeding and even death. It makes they need to be careful of it so bentan will not happen to themselves and their families after giving birth. This study aims to analyze the health care of bentan postpartum mothers in Malay people in Pontianak. This study uses a qualitative descriptive method through a case study approach. This research was conducted in the District of East Pontianak, in the ethnic Malay community of the Malay village. Data was collected through observation, and interviews. The results of the study showed that the bentan experienced by the informants was due to not carrying out postpartum maternal health care for the Malays regularly and obediently. The more health care is violated and not carried out, the more severe the pain experienced by the informants. The conclusion of this study is the Malays in Pontianak highly respect their customs and traditions, especially in health care during the postpartum period. If it violates, then the postpartum mother must be ready to accept the consequences in the form of a Bentan.
\end{abstract}

Kata Kunci: Health Care, Postpartum, Bentan, Tradition, Malay

\section{PENDAHULUAN}

Masa postpartum atau masa nifas adalah masa yang terlihat aman dan terkadang di anggap remeh, sehingga tidak perlu terlalu diperhatikan fisik maupun psikis ibu setelah melahirkan. Padahal, masa nifas adalah masa yang krusial dan rentan terjadi komplikasi yang dapat membahayakan kondisi ibu. Pendarahan postpartum, infeksi, postpartum blues, bahkan kematian menjadi sebuah ancaman dari

\footnotetext{
${ }^{1}$ Dosen Akademi Kebidanan Panca Bhakti Pontianak
} 
komplikasi yang di alami ibu selama masa nifas. Kurangnya kontrol kesehatan pada masa postpartum juga menyumbang tingginya angka kematian pada ibu (AKI). (Triana dkk, 2015)

Pada tahun 2016 di Provinsi Kalimantan Barat, tercatat kematian maternal adalah sebesar 95 per 100.000 kelahiran hidup. Angka kematian ibu di Pontianak di antara 13 kabupaten lain yang ada di Kalimantan barat, yaitu 3 per 100.000 kelahiran hidup. (Kemenkes, 2017 ; ProKes Kal-Bar, 2016 ; ProKes Pontianak, 2017). Kota Pontianak menempati posisi ketiga terendah dalam jumlah angka kematian ibu, setelah Singkawang dan Bengkayang. Derajat kesehatan yang di capai tidak dapat di pisahkan dari budaya dan tradisi yang sudah turun - temurun dijalankan oleh masyarakatnya. Begitu pula di Kota Pontianak yang di dominasi oleh etnis Melayu dengan segala macam tradisi, adat dan kepercayaannya.

Perawatan kesehatan ibu postpartum pada orang Melayu di Pontianak di anggap sebagai perawatan wajib yang harus mereka lakukan setelah melahirkan. Orang melayu percaya bahwa pada masa nifas seorang ibu kesehatannya harus sangat di perhatikan, karena komplikasi yang terjadi pada masa nifas sangat berbahaya bagi ibu dan dapat menyebabkan kematian. Pada suku melayu komplikasi pada masa nifas disebut 'Bentan'. Bentan adalah sebuah kondisi ibu dalam 40 hari setelah melahirkan yang mengalami berbagai komplikasi menyebabkan ibu tidak dapat beraktifitas, bahkan dapat menyebabkan kematian.
Berdasarkan hasil studi pendahuluan peneliti mewawancarai 4 informan yang mengalami komplikasi pada masa nifas atau bentan pada orang melayu di Pontianak. Informan yang di wawancarai masing- masing 1 orang ibu yang pernah melahirkan dan mengalami bentan dari Kecamatan Pontianak Kota, Pontianak Barat, Pontianak Selatan, dan Pontianak Timur. Satu infoman mengatakan tidak percaya pada awalnya dengan anjuran adat istiadat orang melayu, sehingga memilih untuk tidak melakukan dan tetap beraktifitas seperti biasa. Setelah beberapa hari pasca melahirkan, terjadilah bentan sehingga orang tuanya merawat sesuai dengan kepercayaan adat istiadat orang melayu.

Tiga informan lainnya sudah mengikuti sesuai anjuran adat istiadat orang melayu, namun mereka mengatakan bahwa ada pantangan yang mereka langgar sehingga mereka mengalami bentan. Ketiga informan mengatakan bahwa mereka melakukan aktifitas yang di anggapnya ringan bagi ibu rumah tangga seperti mencuci, bersih- bersih rumah, dan mengangkat air. Namun hal itu di anggap melanggar pantangan sehingga mengalami bentan. Ketiga informan mengatakan bahwa mereka melakukan aktifitas yang di anggapnya ringan bagi ibu rumah tangga seperti mencuci, bersih- bersih rumah, dan mengangkat air. Namun hal itu di anggap melanggar pantangan sehingga mengalami bentan.

Selama bentan, orang tua atau dukun yang mereka percaya akan memberikan rebusan tanaman obat, jamu, serta makanan yang di percaya baik untuk ibu nifas. Mereka juga 
memiliki cara penyembuhan yang sudah turun temurun dilakukan untuk mengobati bentan yang disebut 'Ngapoh'. Ngapoh dipercaya merupakan rangkaian pelengkap dalam proses perawatan kesehatan pada masa nifas. Dengan rangkaian perawatan kesehatan yang dilakukan keempat informan yang mengalami bentan, mereka mengatakan bahwa kondisinya mengalami perbaikan dan tubuhnya terasa jauh lebih sehat. Berdasarkan fakta tersebut, maka peneliti tertarik untuk menganalisis perawatan kesehatan ibu postpartum bentan pada orang melayu di Pontianak.

\section{METODE PENELITIAN}

Penelitian ini menggunakan metode penelitian deskriptif kualitatif, dan menggunakan pendekatan studi kasus untuk mengungkap perawatan kesehatan ibu postpartum bentan pada orang melayu di Pontianak. Peneliti menjadi instrumen utama dalam penelitian ini. Penelitian ini dilakukan di Kecamatan Pontianak Timur, dalam komunitas etnik Melayu yang berada di perkampungan Melayu.

Teknik penentuan informan menggunakan snowball sampling. Dalam proses ini peneliti meminta rekomendasi orang- orang yang dapat di wawancarai selanjutnya dari informan kunci. Teknik ini digunakan agar dapat memperoleh informan yang memiliki pengetahuan dan pengalaman terhadap topik penelitian. Informan yang dijadikan subjek dalam penelitian digolongkan kedalam dua golongan, pertama informan kunci yaitu orang yang mengetahui dengan jelas kondisi daerah penelitian dan mampu menunjukan siapa- siapa saja yang dapat memberikan informasi mengenai masalah yang diteliti. Di mana yang bertindak sebagai informan kunci adalah tokoh masyarakat yang disegani dan berperan penting dalam masyarakat dan orang yang membantu proses perawatan kesehatan ibu postpartum pada orang melayu (dukun atau orang tua yang merawat ibu postpartum dengan adat melayu)

Kedua, informan yaitu ibu yang pernah mengalami bentan dan melakukan perawatan masa postpartum pada orang melayu di Pontianak. Orang yang mengetahui tentang masalah yang diteliti yakni komunitas adat melayu, yang memberi informasi secara mendalam tentang pengalaman, pendapat, atau kepercayaan, pengetahuan mengenai nilai, sikap dan tanggapan dalam perawatan ibu post partum pada orang melayu yang di lakukan selama ini.

Data Primer merupakan data utama yang diperoleh dari hasil penelitian. Dalam penelitian ini data primer diperoleh secara langsung dari hasil wawancara mendalam dengan para informan terpilih, yaitu tokoh masyarakat setempat, ibu postpartum, dan dukun/ orang tua yang telah ditentukan sebelumnya sebagai sumber informasi, berupa wawancara mendalam (in-depth interview) tentang perawatan kesehatan ibu postpartum pada orang melayu di Pontianak.

Teknik pengumpulan data dengan menggunakan teknik pengamatan (observasi) dan wawancara mendalam (indepth interview). Observasi penuh dilakukan selama peristiwa ada dan dapat di amati akan di amati, tetapi jika peristiwa tidak ada akan dilakukan observasi 
tidak penuh. Observasi tidak penuh dilakukan dengan menggunakan data sekunder dari informan. Dalam wawancara mendalam, peneliti menentukan waktu yang tepat untuk melaksanakan penelitian, dilanjutkan dengan perkenalan kepada informan kemudian mengajukan pertanyaan dari inti- inti permasalahan kepada informan. Peneliti kemudian mengajukan pertanyaan dari inti- inti permasalahan kepada informan yang di pandang memiliki pengetahuan yang banyak berkenaan dengan masalah studi, serta mampu memberikan informasi tersebut dengan baik.

Analisis data dalam penelitian ini menggunakan teknik analisis data model interaktif Miles dan Huberman, yaitu reduksi data, penyajian data dan kesimpulan/verifikasi.

\section{HASIL}

\section{Bentan}

Bentan adalah bahasa melayu yang berarti komplikasi yang terjadi pada masa nifas, dikarenakan melanggar pantangan atau tidak menjalankan anjuran yang telah di beritahukan. Menurut beberapa informan bentan di ibaratkan seperti 'keteguran', yaitu ibu postpartum di anggap tidak melakukan atau tidak patuh terhadap perawatan kesehatan dengan adat melayu yang sudah dianjurkan. Sehingga ibu tersebut mendapat teguran, dengan penyakit yang tiba- tiba saja menimpanya.

Namun ada pula informan yang menganggap bentan bukanlah keteguran. Bentan adalah sebuah kondisi dikarenakan ibu melakukan aktifitas yang berat seperti menggendong anak, dll. Keteguran sendiri menurutnya datang dari setan dan iblis. Keteguran bisa di karenakan seseorang berjalan keluar saat hujan panas, namun jika kita bertawakal kepada Allah swt. Hal- hal seperti itu sebenarnya tidak akan terjadi, hanya saja kita yang masih khawatir dan tidak percaya janji Allah swt. yang menyebabkan keteguran dapat terjadi.

Menurut penuturan dari dukun dan ibu postpartum yang pernah merasakan bentan. Bentan lebih sakit dari pada melahirkan, sehingga mereka sangat menjaga agar tidak terjadi pada dirinya dan keluarganya. Menurutnya orang yang menjalankan segala pantangan dan anjuran selama masa postpartum pada orang melayu itu baik dan banyak manfaatnya. Perawatan tersebut dapat mempercepat penyembuhan pada ibu postpartum dan mencegah terjadinya hal- hal yang tidak diinginkan seperti peranakan yang turun.

Terdapat perbedaan pendapat terkait bentan dapat menyebabkan pendarahan atau tidak. Pendapat pertama beranggapan bahwa pendarahan bukanlah bentan. Pendarahan menurut para informan terjadi sesaat setelah ibu melahirkan. Menurut mereka darah yang keluar dari vagina mengalir seperti keran, itulah yang disebut pendarahan. Bentan adalah kondisi ibu yang mengigil di karenakan saat melahirkan ibu berteran dan menyebabkan urat- uratnya putus sebanyak 44 buah. Saat hamil, perut ibu yang awalnya tegang karena masih ada bayi, kemudian melahirkan. Perut ibu tiba- tiba kosong, hal ini yang menyebabkan urat- urat 
halus ibu putus, dan jika di biarkan ibu beresiko bentan.

Pendapat yang berbeda diutaran informan lainnya. Mereka berpendapat bahwa pendarahan masuk kedalam kategori bentan. Bentan menurut mereka disebabkan karena ibu postpartum melakukan aktifitas yang berat, seperti membersihkan rumah, dan melanggar pantangan untuk keluar rumah selama masa postpartum. Bentan itu seperti pusing, sakit kepala yang berkepanjangan, tubuh menggigil, dan bengkak pada payudara. Pendarahan bisa saja terjadi pada fase bentan, menurutnya itu disebabkan oleh aktifitas yang terlalu berat, seperti mencuci, dan membersihkan rumah.

\section{Ibu Postpartum Yang Mengalami Bentan}

Dari hasil wawancara kepada Ny. N, Ny. RS dan Ny. SF yang pernah mengalami bentan.

\section{Pengalaman Bentan Ny. S}

Pengalaman bentan yang di alami oleh Ny. SF. Pada kelahiran anak pertamanya beliau tinggal bersama orang tua sehingga ada yang merawat dan Ny. SF tidak mengalami bentan. Beliau mengalami bentan pada kelahiran anak keduanya dikarnakan dia sudah tinggal pisah dengan orang tua dan tidak ada yang merawatnya lagi. Selama masa postpartum beliau tetap melakukan perawatan rutin, namun ada pantangan yang dia langgar. Pantangan yang beliau langgar yaitu melakukan aktifitas berat, seperti mencuci dan membesihkan rumah. Hal itu dia lakukan karena sudah tinggal pisah dengan orang tua, dan tidak ada yang merawatnya selama masa postpartum. Selama bentan beliau menggigil, demam, dan seluruh tubuh terasa sakit. Beliau mengatakan sakitnya lebih sakit dari pada melahirkan.

Beliau menyadari kesalahan yang dilakukannya sehingga terjadi bentan adalah ia lupa memasang bengkung atau stagen, kakinya terlilit dan jempol kakinya tersandung sehingga saat itu juga beliau mengalami bentan. Tubuhnya menggigil dan payudaranya bengkak. Beliau membenarkan bahwa memang seharusnya ibu postpartum melakukan perawatan kesehatan pada orang melayu. Wajib juga menjalankan pantangan dan anjuran yang sudah di beritahukan.

Seperti memasang benang hitam pada jempol kaki. Hal itu menurutnya bukanlah suatu hal yang mistis dan perlu di takuti. Sebaliknya, benang hitam itu digunakan, agar ibu postpartum tetap ingat dan berhati- hati bahwa dia dalam keadaan tidak sehat. Sehingga harus menjaga segala hal pada tubuhnya dengan lebih berhati- hati.

\section{Pengalaman Bentan Ny. RS}

Pengalaman selanjutnya yang dirasakan oleh $\mathrm{Ny}$. RS yang juga mengalami bentan. Ny. RS mempunyai 2 orang anak, dan pada kelahiran anak pertama dan keduanya beliau mengalami bentan. Pada kelahiran anak pertama, berat badan lahir anaknya 3900 gram. Setelah melahirkan beliau jauh dari orang tua, tidak ada yang merawat. Ketika anaknya menangis, beliau juga yang menenangkan dengan cara menggendongnya sambil mengayun- ayunkan badan bayi yang berada di gendongannya. Pada saat itu, Ny. RS baru saja selesai mandi dan 
belum menggunakan bengkung/ stagen, setelah itu beliau pun mengalami bentan. Menurut penuturan dari Ny .RS yang dia rasakan saat itu menggigil yang luar biasa di seluruh tubuh.

Pada saat menggigil, perutnya terasa mulas dan seperti ingin berteran. Luka jahitan di vaginanya terasa mau lepas. Beliau menyadari bahwa saat masa postpartum, ada pantangan yang dia langgar. Seperti mengangkat berat dan melakukan aktifitas yang tidak seharusnya dilakukan ibu postpartum. Anjuran perawatan kesehatan yang lainnya juga tidak dilakukan seperti menggunakan bengkung atau stagen.

Pada kelahiran anak keduanya, Ny. RS juga mengalami bentan. Saat itu beliau mencuci baju dan mengangkat air. Hal ini melanggar pantangan ibu postpartum tidak boleh melakukan aktifitas berat. Sementara perawatan, pantangan dan anjuran selama masa postpartum tidak dilakukan dengan baik. Beliau melakukan perawatan namun tidak dilakukan dengan rutin, seperti tidak menggunakan param, menggunakan bengkung tapi kadang- kadang dan di pasang longgar. Tanpa disengaja juga jempol kaki Ny. RS tersandung selama beraktifitas.

Tubuh dan payudara Ny. RS saat itu mengalami bengkak. Tubuhnya menggigil dan demam. Beliau mengatakan selama bentan, sakit yang di rasakannya lebih sakit dari pada saat melahirkan.

\section{Pengalaman Bentan Ny. N}

Pengalaman yang dirasakan $\mathrm{Ny}$. N saat beliau bentan, pada awalnya dia tidak mengetahui apapun tentang perawatan kesehatan masa postpartum pada orang melayu. Setelah melahirkan beliau tinggal di rumah mertua, merasa bahwa perawatan kesehatan dengan adat melayu itu tidak terlalu penting, jadi dia melakukan perawatan tersebut kadang- kadang saja. Beliau juga tidak perduli dengan pantangan yang ada.

Berselang beberapa hari setelah melahirkan, jempol kakinya tersandung saat akan mengangkat baju di jemuran. Tanpa menunggu waktu lama, saat itu juga beliau mengalami bentan. Bentan yang di rasakannya seperti menggigil yang luar biasa, disertai demam dan payudara bengkak. Darah yang keluar dari vagina cukup banyak, berwarna hitam dan berbentuk balok beku.

Setelah melahirkan, karena tidak menggunakan pilis mata Ny.N bengkak, kemerahan, berair dan gatal yang disebut dalam bahasa melayu 'meroyan'. Beliau di beri tahu oleh dukun yang merawatnya bahwa hal itu diakibatkan karena dia tidak menggunakan pilis. Setelah menggunakan pilis, tidak terasa apaapa. Namun meroyan yang di alami oleh $\mathrm{Ny}$. $\mathrm{N}$ berangsur- angsur sembuh dan tidak gatal lagi.

Dari pengalaman yang dirasakan oleh Ny.N, beliau mengatakan selama bentan rahimnya sempat turun ke saluran vagina atau turun peranakan, dalam bahasa medis prolaps uteri. Beliau tidak mengetahui hal tersebut, setelah melakukan pengobatan dengan dukun yang biasanya merawat ibu postpartum. Beliau baru tau kalau rahimnya keluar ke saluran vagina dan harus di kembalikan seperti semula. Beliau mengatan bahwa bentan yang di alaminya lebih sakit dari pada melahirkan. 


\section{Perawatan Pada Ibu Postpartum Bentan pada}

\section{Orang Melayu di Pontianak}

\section{Perawatan yang dilakukan pada kasus Ny.S}

Kasus bentan yang di alami Ny. S belum masuk dalam tahap bentan yang berat. Beliau melakukan perawatan kesehatan ibu postpartum dengan budaya melayu, namun ada pantangan yang tidak sengaja dilakukan dan anjuran yang lupa di lakukan sehingga mengalami bentan. Pada kasus Ny. S yang dilakukan pada beliau adalah kembali ke perawatan kesehatan rutin ibu postpartum melayu seperti :

(1)Bejah adalah bahasa melayu yang menurut masyarakat setempat sama dengan pencegahan. Sebelum penyakit bertambah parah harus di lakukan pencegahan. Bejah juga di anggap sebagai antibiotik tradisional supaya luka jalan lahir yang di alami ibu setelah melahirkan lebih cepat sembuh, tidak bengkak dan infeksi. bejah dilakukan dengan memanaskan wajan/ kuali, kemudian di letakkan di antara kedua kaki ibu postpartum. Ibu postpartum hanya mengenakan sarung. Wajan/ kuali panas tadi akan di siram dengan rebusan rempah- rempah seperti sari wangi, daun lengkuas, daun pisang klotok, dan daun lempuyang. Selain menggunakan kuali, dapat juga menggunakan cangkang kelapa yang di panggang, kemudian di letakkan di antara kedua kaki ibu dan di siram dengan rebusan rempah- rempah. Diharapkan setelah dilakukan bejah, uap panas naik dan vagina maupun rahim ibu akan kembali ke ukuran semula. Bejah di lakukan hanya sekali sesaat setelah melahirkan. Bejah juga dapat dilakukan dengan cara mengompres luka jalan rahin dengan rempah- rempah yang sudah di tumbuk dan di rebus, kemudian kasa di celupkan pada air rebusan dan di kompreskan ke luka jalan lahir. Air rebusan tadi juga dapat di gunakan untuk ibu membersihkan organ kewanitaannya.

(2) Minum jamu dan rebusan, terdapat 3 jenis rebusan dan jamu yang harus diminum ibu selama 40 hari setelah melahirkan. Tiga jenis rebusan dan jamu itu adalah peluntur, angin, dan urat. Rebusan dan jamu yang pertama kali diberikan kepada ibu postpartum adalah rebusan dan jamu 'Peluntur'. Rebusan dan jamu ini diberikan dengan harapan akan melunturkan darah- darah beku dan kotor yang masih tertinggal di dalam rahim ibu setelah melahirkan. Dengan meminum rebusan dan jamu ini, masyarakat setempat percaya akan membersihkan rahim dan mempercepat proses penyembuhan pada ibu. Rebusan dan jamu peluntur diminum selama kurang lebih 15 hari pasca melahirkan. Di anjurkan untuk makan terlebih dahulu, setelah itu baru minum jamu peluntur. Selang beberapa menit, baru minum rebusan peluntur. Rebusan dan jamu setelah hari ke lima belas pasca melahirkan adalah rebusan dan jamu angin. Rebusan dan jamu ini dipercaya bermanfaat untuk membuang angin yang ada di persendian dan urat- urat ibu yang sedang dalam masa penyembuhan. Rebusan dan jamu angin di minum dari hari ke 15 sampai hari ke 25 setelah melahirkan. Setelah itu dilanjutkan dengan rebusan dan jamu urat sampai hari ke 40 pasca melahirkan. Mereka percaya bahwa ibu 
setelah melahirkan, kurang lebih 44 uratnya putus sehingga harus di satukan kembali dengan meminum rebusan dan jamu urat. Tata cara meminumnya sama dengan rebusan dan jamu peluntur, sebelumnya disarankan untuk makan terlebih dahulu. Urutan dalam meminum ketiga rebusan dan jamu tersebut harus benar yaitu peluntur, angin dan urat. Perbedaan antara Jamu dan Rebusan menurut Ny. SA adalah jamu biasanya sudah di haluskan, sementara rebusan bahan dan rempahnya tidak di haluskan. Rebusan berasal dari akar kayu, daun- daunan dan umbi- umbian yang di keringkan, cara mengolahnya pun harus di rebus terlebih dahulu, air rebusannya yang di minum. Sedangkan jamu, akar kayu tidak dapat di haluskan sehingga di dalam kandungan jamu biasanya hanya terdapat umbi- umbian seperti kunyit, jahe merah, jahe putih, temu kunci, kencur, temu putih, dan lain- lain. Ketumbar, sahang, jintan hitam, kembang peka, kapulaga, adas manis, dan lain- lain bisa masuk di dalam jamu maupun rebusan. Cara mengkonsumsi jamu juga cukup dengan menyeduhnya di dalam air panas jika berbentuk serbuk. Jika berbentuk seperti tablet, cukup dimakan tanpa harus di kunyah terlebih dahulu. Jamu dan rebusan diminum 2 kali sehari, setelah mandi pagi dan mandi sore. Saat merebus rempah- rempah tidak boleh menggunakan panci besi atau pun alumunium, karena dapat merusak kualitas rebusan. Jadi saat merebus yang di gunakan adalah panci yang berasal dari tanah ataupun panci keramik.
(3) Tapal adalah abu bekas pembakaran kayu atau kelapa yang di beri asam jawa, dan rempah- rempah lainnya, di letakkan di atas perut di bawah gurita. Sebelum di pasang gurita, perut ibu akan di beri tapal. Tapal digunakan tergantung kondisi perut ibu. Jika perut ibu masih belum kembali normal, tapal akan terus di gunakan. Namun pada umumnya tapal di gunakan selama kurang lebih 25 sampai 30 hari. Menurut Ny. MB tapal sebaiknya digunakan malam hari. Tujuan menggunakan tapal, agar setelah melahirkan perut yang sempat membesar kembali seperti normal dan tidak bergelambir. Tapal juga dipercaya mengembalikan ukuran rahim agar kembali normal.

(4) Bengkung (stragen), setelah di pasang gurita di perut, selanjutnya perut ibu akan di bengkung (stagen). Menurut kepercayaan bengkung tujuannya untuk mengembalikan bentuk tubuh agar kembali normal, langsing, menghangatkan perut, membantu proses penyembuhan pasca melahirkan dan menjaga agar peranakaan tidak turun. Bengkung di gunakan 3 hari pasca melahirkan sampai 40 hari postpartum. Bengkung tidak hanya di gunakan pada perut, biasanya digunakan juga pada paha, tujuannya untuk membatasi gerak ibu agar proses penyembuhan berjalan cepat.

(5) Param, terbuat dari beras yang di tambahkan dengan rempah- rempah seperti lengkuas, liya (jahe), ketumbar, dll kemudian di tumbuk dan di oleskan ke tubuh. Wajah, tubuh, dan perut bahan rempah- rempahnya sedikit berbeda, tergantung pada tingkat 
panasnya param. Tujuan menggunakan param adalah untuk menjaga kehangatan tubuh, melancarkan peredaran darah sehingga mencegah bengkak pada tubuh dan payudara ibu, juga dapat menghaluskan kulit. Param biasanya digunakan selama 40 hari masa postpartum. Menurut Ny. J, selama masa postpartum tubuh menjadi tidak stabil, badan dingin dan sangat rentan untuk mengigil. Dengan menggunakan param. Tubuh akan menjadi hangat dan kulit akan bersih.

(6) Pilis, bahan dasarnya dari cabai jawa atau kayu sepang. Rempah- rempah tambahan lainnya, tergantung dukun yang meracik. Bahan yang diperlukan untuk membuat pilis adalah cabe jawa, dan kulit jeruk purut, kemudian di sangrai sampai hangus dan di tambahkan jintan hitam, baru digunakan sebagai pilis. Pilis ini berguna untuk mencegah darah naik ke mata dan mencegah kebutaan pada usia tua. Pilis juga dapat di buat dari kayu sepang yang diasah dengan kapur, kemudian baru dioleskan merata di dahi atas alis. Setiap dukun memiliki ramuannya masing- masing. Pilis digunakan kurang lebih selama 20 hari pasca melahirkan.

(7) Pijat, selama 40 hari masa postpartum, ibu akan di pijat seluruh tubuh oleh dukun beranak. Namun ini tidak dilakukan setiap hari, tapi dilakukan hanya pada hari ke 3 , ke 7, ke 17, ke 25, dan terakhir hari ke 40. Pijat dilakukan 5 kali selama 40 hari pasca bersalin. Menurut kepercayaan tujuan pijat pada ibu postpartum adalah untuk melepaskan ketegangan pada otot, mengeluarkan darah- darah beku setelah melahirkan, pijat juga dapat memperlancar peredaran darah dan oksigen kedalam otot sehingga meredakan nyeri dan pegal- pegal.

Pantangan dan anjuran selama masa nifas, yaitu:

(1) Makanan yang di konsumsi, makanan yang diolah dengan di goreng, diperbolehkan namun harus di garis bawahi tidak boleh terlalu banyak minyak. Jika menggoreng tanpa sengaja banyak minyak, disarankan untuk di tiriskan terlebih dahulu, baru di konsumsi. Makanan yang di sarankan adalah makanan yang di rebus, di panggang, tidak pedas dan lebih baik tanpa minyak. Sayur yang dimasak juga di sarankan dimasak bening tanpa santan. Sayuran yang baik dikonsumsi adalah sayur bayam kemudian di tambah jahe dan kacang hijau, jagung, cangkok manis atau daun katuk, jantung pisang tidak boleh di tambah minyak saat memasaknya. Jenis ikan yang tidak boleh dimakan adalah ikan puput, ikan tongkol,dan ikan gembung, sedangkan ikan yang boleh dimakan adalah ikan tenggiri, dan ikan gelama.

(2) Selanjutnya adalah aktifitas yang sebaiknya tidak di lakukan pada ibu postpartum adalah aktifitas yang telalu berat. Dengan melakukan aktifitas yang berat di khawatirkan jumlah ASI akan berkurang, dan mengganggu kesehatan ibu postpartum yang sedang dalam masa penyembuhan.Segala aktifitas yang dilakukan harus penuh dengan kehati- hatian, termasuk cara berjalan dan tidur. Berjalannya ibu postpartum harus 
pelan dan tidak boleh melangkah terlalu lebar. Ibu postpartum harus sangat berhatihati jangan sampai ketika berjalan, jempol kaki terpengkak atau tersandung. Sehingga jempol kaki ibu postpartum pada orang melayu, akan di pasang benang hitam yang dipintal atau ijuk, agar tidak terjadi bentan pada ibu. Pada ibu postpartum harus lurus, tidak boleh melengkung atau miring, karena jika ibu tidur melengkung dan miring ditakutkan tubuh akan bergelambir. Dianjurkan juga kaki di letakkan sedikit lebih tinggi dari tubuh, bisa di sanggah dengan bantal agar kaki tidak bengkak dan mencegah varises. Saat tidur ibu postpartum juga tidak diperbolehkan mengangkat tangan, mengangkat tangan ketika menjemur pakaian juga tidak boleh karena di khawatirkan air susu ibu akan bengkak dan kering. Selama 40 hari masa postpartum disarankan untuk tidak keluar dari rumah, bahkan pada zaman dahulu ibu postpartum tidak di perbolehkan turun dari tempat tidur kecuali ke kamar mandi. Semua aktifitas yang hendak dilakukan ibu, seperti menyusui, makan, ke kamar mandi akan di bantu.

(3) Pakaian yang di kenakan oleh ibu postpartum pada orang melayu tidak ada yang khusus. Namun disarankan pada masa postpartum mengenakan baju berkancing depan untuk mempermudah saat menyusui bayinya, dan kain sarung untuk mempermudah ke kamar kecil.

Setelah melakukan berbagai perawatan rutin selama masa postpartum, $\mathrm{Ny}$. S merasakan tubuhnya jauh lebih sehat dari sebelumnya. Bentan yang di alaminya pun mengalami perbaikan yang cepat.

\section{Perawatan yang dilakukan pada kasus $\mathbf{N y}$. RS}

Kasus bentan yang di alami Ny. RS kurang lebih sama dengan Ny. S namun sudah masuk ke bentan yang berat. Beliau mengalami bentan dua kali pada kelahiran anak pertama dan keduanya. Pada kelahiran anak pertama, perawatan yang di lakukan yaitu kembali ke perawatan rutin yang wajib di lakukan ibu postpartum pada orang melayu.

Saat badan dan payudaranya bengkak, beliau menggunakan param di seluruh tubuh. Pada payudara beliau menggunakan asam jawa, kunyit dan kapur. Sebelumnya payudara diolesi minyak makan atau minyak kayu putih. Setelah itu baru diberi asam jawa, kunyit, dan kapur yang telah di haluskan. Beliau mengatakan bahwa setelah menggunakan param, beliau aktif buang kecil dan keesokan harinya tubuh dan payudara yang bengkak sudah mengempis.

Beliau juga melakukan perawatan kesehatan khusus pada ibu postpartum bentan yaitu ngapoh. Sebelum melakukan apoh, dukun yang merawat selama masa nifas akan melakukan ritual 'buang- buang', Buang- buang dilakukan untuk memohon keselamatan dan meminta kesembuhan. Buang- buang adalah ritual yang dilakukan dengan cara membuang seperti gambir, pinang, rokok daun, telur, paku, dan keminting kulit. Semua bahan- bahan tadi dimasukan kedalam tempat- tempat kecil dari 
daun pisang, kemudian di alirkan ke sungai Kapuas.

Buang- buang dilakukan dengan tujuan untuk memohon keselamatan pada leluhur. Ngapoh atau di apoh adalah menggunakan besi yang di bakar sampai benar- benar panas. Ibu postpartum hanya menggunakan kain sarung, dan besi panas tadi diletakkan di antara kedua kakinya. Kemudian dukun/ orang tua yang mengetahui rempah- rempah (sirih, kapur, gambir, cekur dan serai) dan doa untuk apoh ini, akan mengunyah rempah- rempah tadi hingga halus, setelah itu minum air sedikit. Setelah tercampur dengan air, ramuan tadi di semburkan ke kuali panas yang sudah ada di antara kaki ibu postpartum. Diharapkan, uap panas dari kuali besi yang disembur naik ke ibu dan dapat menyembuhkan ibu yang terkena bentan tadi. Dilakukan pada sore hari, karena di sore hari menurut kepercayaan matahari sedang turun, diharapkan demam juga akan turun.

Setelah di apoh/ ngapoh yang Ny. RS rasakan tubuhnya terasa nyaman, luka jahitannya tidak sakit, perutnya yang awalnya mulas tidak lagi setelah dilakukan apoh/ ngapoh ini. Beliau hanya melakukan apoh/ ngapoh selama bentan sebanyak tiga kali saja, karena setelah itu bentan yang di alami Ny. RS sudah sembuh. Beliau memasang benang hitam di kedua jempol kakinya. Benang itu di percaya oleh orang melayu sebagai penangkal bentan, meskipun beliau tidak terlalu percaya tetapi tetap dilakukannya. Setelah ia mulai rutin melakukan semua yang di anjurkan, dan menghindari pantangan kondisinya pun perlahan pulih kembali.
Perawatan yang dilakukan pada kasus $\mathrm{Ny} \cdot \mathrm{N}$

Kasus bentan yang dialami oleh Ny.N lebih berat dari kasus bentan yang di alami Ny.S dan Ny. RS. Beliau mengalami bentan sampai dengan rahimnya turun ke vagina. $\mathrm{Ny} . \mathrm{N}$ juga sempat mengalami pendarahan saat bentan. Perawatan kesehatan masa postpartum, pantangan, anjuran tidak di lakukan oleh $\mathrm{Ny}$. N, sehingga dia mengalami bentan. Setelah mengetahui hal tersebut, beliau mulai melakukan perawatan kesehatan ibu postpartum pada orang melayu secara rutin. Di mulai dari perawatan pada umumnya, beliau minum jamu, menggunakan bengkung atau stagen, menggunakan param, pilis, dan memasang benang hitam di jempol kakinya, serta mulai memperhatikan pantangan- pantangan yang ada. Beliau juga melakukan perawatan untuk ibu postpartum bentan, seperti ngapoh dan ngangkil. Selain perawatan dengan adat melayu, beliau juga minum obat dari dokter.

Selama bentan, Ny. N juga merasakan di apoh. Selama di apoh yang dirasakannya adalah sakit namun cuma sebentar. Setelah itu rasanya nyaman, dan kondisinya berangsur- angsur membaik. Namun menurutnya, yang menyebabkan kondisinya membaik bukan hanya karna apoh. Tetapi juga karena rangkaian perawatan kesehatan yang lainnya. Dari yang Ny. $\mathrm{N}$ rasakan, pada awalnya luka jahitannya perih setiap akan buang air kecil. Setelah di apoh, buang air kecilnya menjadi lancar dan tidak perih lagi.

Ngangkil ada perawatan yang di lakukan untuk menaikkan rahimnya yang turun. Ngangkil adalah menekan urat perut untuk 
menaikkan peranakkan. Posisi tangan dukun di letakkan di bawah perut di atas kemaluan. Posisi ibu postpartum baring, kaki ditekuk (dorsal recumbent). Bagian luar vagina di lapisi dengan kapas. Dengan dua tangan dan posisi duduk, dukun akan melakukan ngangkil sambil meletakkan tangan di antara perut dan kemaluan, kemudian mengurut ke bagian atas ke arah dada. Hal itu dilakukan sambil menekan vagina ibu dengan tumit kaki. Tujuannya agar rahim yang turun, naik kembali ke posisinya semula. Setelah dilakukan ngangkil rahimnya pun kembali ke posisi semula. Setelah melakukan berbagai perawatan kesehatan ibu postpartum rutin dan bentan kondisinya pun berangsur- angsur membaik.

Menurut pengalaman $\mathrm{Ny}$. N yang pernah mengalami bentan, setelah melakukan perawatan kesehatan dengan adat melayu, beliau menyadari bahwa perawatan kesehatan tersebut penting dan banyak manfaatnya. Menurutnya perawatan kesehatan pada masa postpartum tidak hanya menggunakan obat dokter, namun di kombinasikan dengan obat tradisonal akan lebih baik

\section{PEMBAHASAN}

Dari ketiga kasus di atas, pengalaman bentan yang di alami oleh Ny. S, Ny. RS, dan Ny. N semuanya mengalami bentan yang dikarenakan tidak menjalankan perawatan, pantangan dan anjuran dengan rutin dan patuh. Ny. S mengalami bentan karena melanggar sedikit pantangan saja, meskipun dia sudah melakukan perawatan dan anjuran lainnya. Ny.RS melanggar beberapa pantangan dan tidak menjalankan perawatan dengan rutin dan patuh. Sedangkan $\mathrm{Ny}$. $\mathrm{N}$ tidak menjalankan perawatan dengan rutin dan patuh, dan tidak memperdulikan pantangan dan anjuran yang ada. Dapat dilihat dari tingkatan bentan nya, bahwa semakin banyak pantangan dan anjuran yang dilanggar, serta perawatan kesehatan masa postpartum yang tidak dilakukan dengan rutin dan patuh, bentan yang di alami juga semakin parah.

Perawatan kesehatan masa postpartum pada orang melayu di Pontianak adalah perawatan yang wajib dilakukan. Menurut penuturan para pemuka adat melayu dan dukun yang biasa merawat ibu postpartum. Jika tidak menjalankan perawatan kesehatan dengan rutin dan patuh, tidak memperdulikan pantangan yang sudah di beritahukan akan mengalami bentan. Perawatan kesehatan pada masa postpartum yang dilakukan oleh orang melayu menjadi sebuah rangkaian apik dan saling ketergantungan.

Perawatan kesehatan ini memiliki makna dan fungsinya masing- masing sehingga di lakukan dari generasi ke generasi. Perawatan kesehatan pada masa postpartum dimulai sesaat setelah melahirkan sampai 40 hari setelah melahirkan. Perawatan kesehatan masa postpartum yang umum dilakukan oleh orang melayu adalah bejah, minum jamu dan rebusan, bertapal, menggunakan param dan pilis, kemudian tubuh ibu di pijat selama 40 hari.

Bentan di anggap sebagai teguran dan hukuman karena sudah melanggar sumpah. Dari hasil wawancara dengan informan yang pernah merasakan bentan, mereka mengatakan bahwa 
sakitnya bentan lebih sakit dari pada melahirkan. Semua informan yang mengalami bentan, di karenakan mereka melanggar pantangan dan tidak melakukan anjuran yang di beritahukan, seperti beraktifitas terlalu berat, jempol kaki tersandung, tidak memakai bengkung, tidak memakai param, pilis, dan lain- lain.

Gejala yang di alami selama bentan semuanya hampir sama, yaitu menggigil, demam, payudara bengkak. Pada tingkat bentan yang cukup parah, bisa sampai pendarahan dan turun peranakan(rahim) ke saluran vagina. Tidak memasang benang hitam pada kedua jempol kaki, juga dipercaya menjadi penyebab bentan. Ngapoh/ apoh adalah perawatan bentan yang di khususkan untuk ibu postpartum bentan yang sakitnya sudah berat. Ngapoh/ apoh di anggap sebagai sumpah ibu postpartum bentan agar tidak lagi melanggar pantangan dan anjuran yang sudah di beritahukan.

Secara filosofis pendekatan tradisional komplementer memang berbeda dengan pengobatan konvensional. Prinsip pengobatan tradisional adalah pendekatan holistik (mind body spirit), modalitas yang di pakai komprehensif (intervensi mind body spirit), pengobatan lebih kepada vitalitas tubuh atau self healing, dan pengukuran hasil pengobatan bersifat holistik (perbaikan fungsi tubuh). Regulasi dan klasifikasi tersebut ditunjukkan untuk menghindari pseudosains dalam dunia medis terkait pelayanan pengobatan tradisional. (Tjandra Yoga Aditama, 2014)

Pencegahan menggunakan obat- obatan herbal kini semakin di galakkan. Jamu dan rebusan dari berbagai tanaman obat di buat dan terbukti menjadi alternatif pada berbagai penyakit. Berbagai penelitian dilakukan untuk mengetahui manfaat dan efektifitas jamu. Dalam penelitian yang dilakukan Hasanah dan Widowati (2014), dilakukan sebuah penelitian observasi, purposif dan deskriptif terhadap dokter praktik jamu secara komplementeralternatif dengan menggunakan jamu di 9 dari 12 provinsi wilayah Sentra Pengembangan, Penerapan dan Pengobatan Tradisional (SP3T) di Indonesia selama 6 bulan penelitian.

Perubahan yang terjadi adalah perubahan ke arah perbaikan, berupa hilangnya gejala penyakit. Gejala klinis yang paling banyak hilang pada anamnesa gejala saat follow up yaitu pada sistem neurologis (33\%) dan sistem muskuloskeletal (31\%). Tak kalah pentingnya adalah perbaikan gejala umum (23\%), karena 3 dari 4 gejala umum (tidak nafsu makan, letih, dan penurunan berat badan) merupakan gejala yang paling sering ditemui pada penderita rematoid artritis. Meskipun demikian perbaikan gejala klinis ini belum bisa dipastikan sematamata karena efek terapi jamu saja, karena selain jamu digunakan pula terapi konvesional lainnya. (Hasanah dan Widowati, 2014)

Dari penelitian di atas jamu memberikan dampak yang baik untuk kesehatan tubuh. Namun, perbaikan gejala klinis belum bisa dipastikan semata-mata karena efek terapi jamu saja, karena selain jamu digunakan pula terapi konvesional lainnya. Seperti halnya dalam perawatan kesehatan masa postpartum dengan budaya melayu, jamu menjadi bagian dalam rangkaian perawatan. Belum terdapat uji pra klinik yang memastikan bahwa jamu saja akan 
memperbaiki kondisi ibu postpartum, karena terdapat rangkaian perawatan kesehatan masa postpartum yang dilakukan. Harus terbukti secara empiris melalui tahapan uji pra klinik agar keamanan dan khasiatnya dapat di buktikan. (Khadijah, Anwar, dan Rusman., 2019)

\section{KESIMPULAN}

Suku Melayu di Pontianak sangat menjunjung tinggi adat dan tradisinya terkhusus dalam perawatan kesehatan pada masa postpartum. Terdapat perawatan kesehatan masa postpartum rutin yang wajib dilakukan, terdapat pula pantangan dan ajuran yang harus di hindari dan lakukan. Jika melanggar, maka ibu postpartum harus siap menerima akibatnya berupa bentan. Bentan adalah komplikasi selama masa postpartum dikarenakan tidak menjalankan perwatan keseahtan rutin, melanggar pantangan dan tidak menjalankan anjuran yang ada.

Menurut penuturan informan sakitnya lebih sakit dari pada melahirkan. Perawatan kesehatan masa postpartum yang umum dilakukan oleh orang melayu adalah bejah, minum jamu dan rebusan, bertapal, menggunakan stagen, menggunakan param dan pilis, kemudian tubuh ibu di pijat selama 40 hari. Selain perawatan rutin yang dilakukan, terdapat pula pantangan dan anjuran selama masa postpartum pada orang melayu di Pontianak.

Pantangan dan anjuran tersebut berupa makanan yang di konsumsi, aktifitas yang boleh dan tidak boleh dilakukan, dan pakaian yang sebaiknya digunakan selama masa postpartum.
Tidak hanya itu, perawatan kesehatan bagi ibu yang mengalami bentan juga ada, seperti ngapoh atau apoh dan ngangkil. Perawatan ini tidak lepas dari unsur kepercayaan yang kuat terhadap roh halus atau jimat, berupa penggunaan benang hitam yang di pintal atau ijuk. Di gunakan di kedua jempol kaki, dengan keyakinan akan menjaga ibu tidak terkena bentan (komplikasi selama masa postpartum).

\section{DAFTAR PUSTAKA}

1. Darwis dan Hikmawati. (2017). Kesehatan Masyarakat dalam Prespektif Sosioantropologi. Makassar : CV Sah Media

2. Emzir. (2016). Metode Penelitian Kualitatif Analisis Data. Jakarta : Rajawali Pers

3. Khadijah, Siti., Anwar, R.K., Rusmana, A. (2019). Komunikasi Budaya dan Dokumentasi Kontemporer. Bandung : Unpad Press

4. Rafiek, M. (2012). Ilmu Sosial dan Budaya Dasar. Yogyakarta : Aswaja Pressindo

5. Rini, Susilo, \& Kumala, Feti. (2016). Panduan Asuhan Nifas dan Evidence Based Practice. Yogyakarta : Deepublish

6. Riva'i, Kardian,A. (2016). Komunikasi Sosial Pembangunan. Pekanbaru : Hawa dan Ahwa

7. Rosa, Fitria., Hermita, Neni., \& Samsudin, Achmad. (2017). Karya Sastra Melayu Riau. Yogyakarta: Deepublish

8. Sugiyono. (2014). Metode Penelitian Kuantitatif, Kualitatif dan R\&D. Bandung : Alfabeta 
9. Tim Pengembang Ilmu Pendidikan FIPUPI. (2019). Ilmu dan Aplikasi Pendidikan. Bandung :Imperrial Bhakti Utama

10. Aditama, Tjandra Yoga. (2014). Jamu dan Kesehatan. Jakarta : Badan Penelitian dan Pengembangan Kesehatan Kementrian Kesehatan

11. Triana, Ani., Damayanti, I.P., Afni, Rita., \& Yanti, J.S. (2015). Kegawatdaruratan Maternal dan Neonatal. Yogyakarta : Deepublish.

12. Badan Penelitian dan Pengambangan Daerah Provinsi Jawa Barat. (2018). Kepercayaan dan Praktik Budaya pada Masa Kehamilan Masyarakat Desa Karangsari, Kabupaten Garut. Sosiohumaniora - Jurnal Ilmu-ilmu Sosial dan Humaniora Vol. 20, No. 2, Juli 2018: 162 - 167 ISSN 1411 - 0903 : eISSN: 24432660

13. Hasanah, S.,N. dan Widowati, L. (2014). Model Analisis Terapi Jamu sebagai Komplementer terhadap Perbaikan Keluhan Pada Pasien Artritis. Media Litbangkes, Vol. 25 No. 3, September $2015,177-184$

14. Mahiti, G. R., Mbekenga, C. K., Kiwara, A. D., Hurtig, A., Goicolea, I., Reuben, G., ... Kiwara, A. D. (2017). Perceptions about the cultural practices of male partners during postpartum care in rural Tanzania : a qualitative study, 9716(October). https://doi.org/10.1080/16549716.2017.13 $\underline{61184}$

15. Murniasih,N.,P. Masfiah, S. dan Haryadi, B. (2016). Perilaku Perawatan Kehamilan dalam Prespektif Budaya Jawa di Desa Kaliori Kecamatan Kalibagor. Jurnal Kesmas Indonesia, Volume 8 No 1, Januari 2016, Hal 56-66

16. Parekh, Natasha., Jarlenski, Marlan., \& Kelley, David. (2018). Prenatal and Postpartum Care Disparities in a Large Medicaid Program. Maternal and Child Health Journal (2018) 22 : 429- 437 https://doi.org/10.1007/s10995-017-2410$\underline{0}$

17. Paul, J., Semasaka, S., Krantz, G., Nzayirambaho, M., Munyanshongore, C., Edvardsson, K., \& Mogren, I. (2019). “ Not taken seriously "- A qualitative interview study of postpartum Rwandan women who have experienced pregnancy-related complications, 1-18.

18. Rahayu, Inong., Mudatsir., \& Haballah, Kartini. (2017). Faktor Budaya dalam Perawatan Ibu Nifas. Jurnal Ilmu Keperawatan (2017) 5:1 ISSN: 2338-6371, e-ISSN 2550-018X

19. Reiza, Yaumil. (2018). Budaya Nifas Masyarakat Indonesia, Perlukah dipertahankan? Jurnal Budaya Nifas Masyarakat Indonesia eJKI Vol. 6, No. 1 April 2018 DOI: 10.23886/ejki.6.8060.

20. Ritonga, Syafii Akmal. (2017). Asimilasi Budaya Melayu terhadap Budaya Pendatang di Kecamatan Senapelan Kota Pekanbaru. Jurusan SosiologiFakultas Ilmu Sosial Dan Ilmu PolitikUniversitas Riau. JOM FISIP Vol.4No.2 -Oktober2017

21. Suplee, Patricia., Stuebe, Alinson., \& Bingham, Debra. (2016). National 
Initiative to Improve Systems for

Postpartum Care. Matern Child Health J
(2016) 20:S66-S70 DOI 10.1007/s10995-

016-2171-1 